\title{
O Problema na Modelagem Matemática: determinação e transformação
}

\section{The Problem in Mathematical Modeling: determination and transformation}

\author{
Rodrigo Dalla Vecchia* \\ ORCID iD 0000-0002-5914-985X \\ Marcus Vinicius Maltempi** \\ ORCID iD 0000-0001-5201-0348
}

\begin{abstract}
Resumo
Este artigo tem por objetivo discutir o conceito de problema em Modelagem Matemática no contexto abrangido pela Educação Matemática. Trata-se de resultado de uma pesquisa, norteada pela metodologia qualitativa, em que realizamos um curso envolvendo a construção de jogos eletrônicos. A pergunta diretriz assumida é: como se mostra o problema no processo de Modelagem Matemática envolvido na construção de jogos eletrônicos por alunos de um curso de Licenciatura em Matemática? Como principal referencial teórico trazemos a visão deleuziana de problema, que não associa o problema à dúvida nem à pergunta, colocando-o em um estado não atual. A análise de dados, aliada a um aprofundamento teórico-filosófico, apresenta possíveis consonâncias entre essa visão e as atividades de Modelagem Matemática desenvolvidas. Como resultado, apresentamos que o modo como o problema é determinado condiciona os encaminhamentos das situações desenvolvidas e, consequentemente, o próprio processo de Modelagem Matemática.
\end{abstract}

Palavras-chave: Educação Matemática. Mundo Cibernético. Realidade. Scratch.

\begin{abstract}
In this paper, we discuss the problem concept in Mathematical Modeling in the context of Mathematics Education. It is the result of a research guided by a qualitative methodology, where we set a course involving the construction of electronic games. As the main theoretical reference, we bring Deleuze's problem vision, that is not associated with doubt or question, but with a non-actual state. Data analysis combined with a theoretical and philosophical depth, led to the construction of a problem concept aligned with the mathematical modeling activities we developed. As a result, we show that the way the problem is determined conditions the developed situations and, therefore, the process of Mathematical Modeling.
\end{abstract}

Keywords: Mathematics Education. Cyber World. Reality. Scratch.

\footnotetext{
* Doutor Universidade Estadual Julio de Mesquista Filho (UNESP). Professor do Programa de Pós Grduação em Ensino de Matemática da Universidade Federal do Rio Grande do Sul (UFRGS), Porto Alegre, Rio Grande do Sul, Brasil. Endereço para correspondência: Av. Bento Gonçalves, 9500 Prédio 43-111. Bairro Agronomia Porto Alegre, RS, Brasil CEP: 91509-900. E-mail: rodrigovecchia@gmail.com.

** Livre Docente em Educação Matemática pela Universidade Estadual Paulista (UNESP), Rio Claro/SP. Professor do Programa de Pós-Graduação em Educação Matemática e do Departamento de Estatística, Matemática Aplicada e Computação da UNESP, Rio Claro/SP. Endereço: Avenida 24A, 1515, Bela Vista, Rio Claro, São Paulo, Brasil, CEP 13506-900. E-mail: marcus.maltempi@unesp.br.
} 


\section{Introdução}

Nosso objetivo principal neste artigo é discutir o conceito de problema no contexto da Modelagem Matemática (MM) sob o viés da Educação Matemática. Tanto na literatura nacional (BARBOSA, 2001; ARAÚJO, 2002; BASSANEZI, 2004; BIEMBENGUT, HEIN, 2007; JAVARONI, 2007; MALHEIROS, 2008; KLÜBER, 2012; WEINGARTEN, 2015), quanto na literatura internacional (POLLAK, H., 2007; BORROMEO FERRI, R.; BLUM, 2010; KAISER, G.; SCHWARZ, B.; TIEDEMANN, S, 2010) é possível perceber que as discussões acerca de MM envolvem também a ideia de problema.

Conforme Dalla Vecchia (2009, 2012), a ideia de problema (e também de realidade) parece ser um aspecto que perpassa, de modo direto e indireto, distintas concepções de MM. Esse aspecto pode ser reforçado em trabalhos com vasta pesquisa bibliográfica como as de Klüber (2012), que buscam compreensão acerca da Modelagem Matemática no âmbito da Educação Matemática, apontando o problema como sendo um dos aspectos que se mostra.

Como forma de contextualizar o modo como o problema se relaciona com a MM, trazemos uma visão clássica e comumente aceita no cenário investigativo nacional e internacional, dada por Borromeo Ferri e Blum (2010). Na perspectiva desses autores, o processo de MM é visto como um ciclo e denotado por ciclo de modelagem (Figura 1), que parte de uma situação real problemática.

Nessa forma de conceber a MM, há um conjunto de passos que são seguidos e iniciam após a tarefa ser dada. O primeiro passo é, segundo os autores, imaginar a situação construindo um modelo para ela. Essa situação é simplificada, estruturada e idealizada, criando-se associações entre a situação investigada e a Matemática. Após essa idealização, a estrutura é vista sob o ponto de vista da Matemática e trabalhada matematicamente até encontrar resultados, também matemáticos. Esses resultados são interpretados na situação real, sendo validados ou não. Se não forem validados, o ciclo recomeça, caso contrário o processo se encerra com a exposição do resultado obtido. 


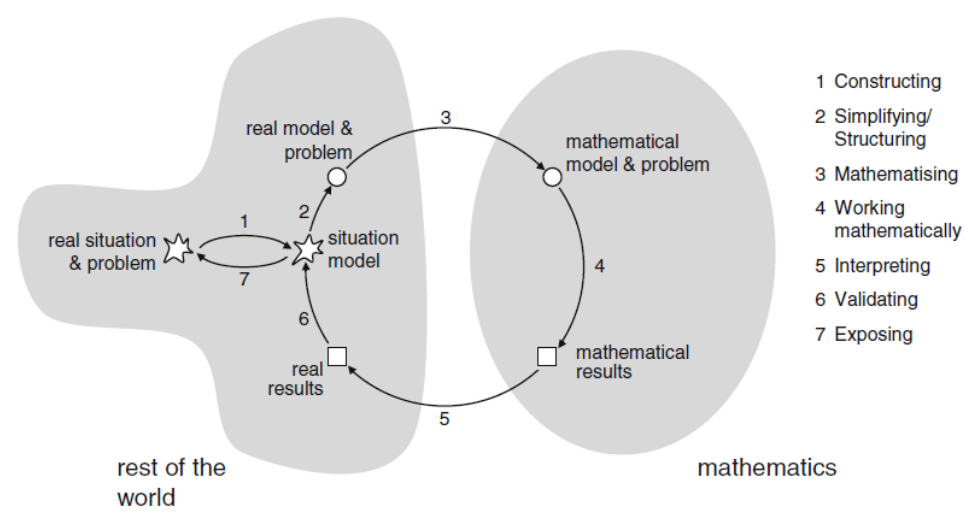

Figura 1 - Ciclo de modelagem

Fonte: Borromeo Ferri; Blum (2010, p. 426).

Com pequenas variações dessa visão, podemos ainda citar autores como Bassanezi (2004), Biembengut e Hein (2007) e Kaiser, Schwarz e Tiedemann (2010) que, de modo geral, mostram o aspecto apontado por Araújo (2002), iniciando o processo de MM a partir de uma situação problemática e culminando com uma solução por meio de um modelo matemático.

Consideramos que o fato do problema ser parte fundamental do processo de MM, já justifica um aprofundamento em seu entendimento, ainda mais que, em nossa revisão de literatura, praticamente não encontramos artigos e pesquisas que focam nesse aspecto. Entretanto, o principal motivador para investirmos em um aprofundamento no conceito esteve relacionado à necessidade que sentimos ao buscarmos compreensões acerca dos desdobramentos que o problema sofria ao longo do processo de MM em uma investigação na qual estudantes de um curso de Licenciatura em Matemática eram convidados a construir jogos eletrônicos por meio da linguagem de programação Scratch ${ }^{1}$. Nesse caso, entendemos que a literatura existente não dava sustentação para explicar aquilo que vivenciávamos naquela investigação.

Com base nessa necessidade, levantamos como pergunta diretriz para o escopo desse artigo o seguinte questionamento: como se mostra o problema no processo de Modelagem Matemática envolvido na construção de jogos eletrônicos por alunos de um curso de Licenciatura em Matemática? Consideramos que, para buscar indícios de respostas, era necessário contrastar os dados obtidos junto aos alunos com referências que trouxessem uma visão não superficial de problema.

Dentre as visões que encontramos, nos inspiramos na trazida por Deleuze (1988), que afirma que o problema não pode ser confundido com a dúvida, nem com a pergunta e não se

\footnotetext{
${ }^{1}$ Esse recurso será discutido na seção de metodologia.
} 
subordina a nenhuma proposição que a ele se refere. Nesse contexto, a forma como o problema é descrito, mostra apenas uma das potenciais interpretações para ele, subordinada ao contexto histórico-social e à linguagem usada para sua determinação. Neste artigo, aprofundaremos essa visão entrelaçando-a com o processo de MM.

Enfatizamos que buscaremos fazer associações que devem ficar no âmbito de uma inspiração no conceito de problema trazido. Desse modo, não se trata de considerar o problema em MM como uma trama de tendências que abrange todos os aspectos identificados por Deleuze (1988). Queremos apenas nos servir de suas ideias para buscar pontos de vista que nos permitam criar linhas de fuga distintas das comumente consideradas na área investigativa específica da MM no âmbito da Educação Matemática. O que buscamos é consolidar um modo de compreender o problema que apresente aspectos consonantes com o processo de construção de modelos na MM encontrados em nossa produção de dados.

Visando alcançar nosso objetivo, apresentaremos o aporte teórico-filosófico que embasa a visão de problema que assumimos. Em seguida, traremos os elementos metodológicos da investigação, orientada pelos pressupostos da pesquisa qualitativa. Com o intuito de dar indícios à pergunta diretriz, traremos os dados buscando um entrelaçamento com o referencial, mostrando o surgimento de dúvidas e de perguntas que foram responsáveis pela determinação de todo o processo de modelagem. Por fim, faremos uma reflexão que associa o problema ao processo de MM.

\section{Problema: aspectos teóricos}

Segundo o dicionário de filosofia Abbagnano (2007), o termo problema foi elaborado inicialmente pela Matemática antiga e usado para designar uma classe de situações que se diferenciavam da noção de teorema. Enquanto o teorema era concebido pelos matemáticos como qualquer proposição demonstrável, o problema era visto como qualquer proposição que partia de certas condições conhecidas (e assumidas como verdadeiras), para buscar alguma coisa desconhecida. Essa perspectiva é trazida desde a Grécia antiga e ganhou força nas ideias de Kant, que entende que "[...] problemas são proposições demonstráveis que exigem provas ou expressam uma ação cujo modo de execução não é imediatamente certo" (ABBAGNANO, 2007, p. 934).

Essa visão é criticada por Deleuze (1988), que entende que compreender o problema desse modo remete a uma subordinação dele ao contexto abrangido pela Matemática e, consequentemente, pelas ciências. Segundo esse autor, ao assumir essa visão, todo problema 
será considerado como tal somente se puder ser decalcado em "[...] proposições que se supõem preexistentes, opiniões lógicas, teoremas geométricos, equações algébricas, hipóteses físicas” (DELEUZE, 1988, p. 264). Por conseguinte, há automaticamente uma redução dos problemas somente às formas de proposição que são capazes de lhes servir como casos de solução, fazendo com que o problema seja avaliado, segundo sua possibilidade de receber uma resposta no contexto científico.

A crítica levantada por Deleuze (1988) se potencializa no presente artigo, principalmente se levarmos em consideração a relação entre ciência e realidade e o papel da Modelagem Matemática nesse entrelaçamento. Segundo Granger (1994), a ciência se refere ao real, mas apresenta uma visão particular dele, dada segundo suas perspectivas e segundo seus métodos. Tal visão, conforme Bicudo e Rosa (2010), não abrange a experiência vivida no âmbito do particular. Sendo assim, nos parece válido buscar uma compreensão de problema que extrapole o contexto da ciência e se diferencie da apresentada em Abbagnano (2007).

No contexto que abrange a Educação Matemática - em particular na Resolução de Problemas - a perspectiva de compreender problemas num campo que envolve somente a ciência é atenuada. De fato, autores como Echeverría e Pozo (1998, p. 15) entendem o problema como sendo "uma situação que um indivíduo ou grupo quer ou precisa resolver e para a qual não dispõe de um caminho rápido e direto que o leve à solução”. Similarmente estão autores como Onuchic e Allevato (2005, p. 221), que entendem problema como “[...] tudo aquilo que não sabemos fazer, mas que estamos interessados em fazer".

O que observamos dessas citações é que há distinções frente à perspectiva de considerar o problema como sendo uma proposição demonstrável e que exige provas, apresentada em Abbagnano (2007). Embora em comum com essa ideia exista a consideração de não uniformidade de encaminhamentos, parece haver implícito às considerações dadas nas duas últimas citações uma abordagem subjetiva e intersubjetiva, que leva em consideração os envolvidos no processo. Em outras palavras, os problemas abrangem uma dimensão particular que se distingue de outras situações que se apresentam ao indivíduo (ou grupo) pelo fato de não conhecer caminhos que levam à solução.

Com uma visão que também considera aspectos subjetivos na MM está a perspectiva defendida por Borba, Malheiros e Zullato (2007, p. 99-100), que entendem que o problema pode ser visto como "[...] algo com uma parte subjetiva e outra objetiva, sendo a primeira relacionada a um interesse pessoal e a segunda ligada a um obstáculo que de fato se apresenta na existência da experiência de uma pessoa ou grupo". Para elaborar essa visão, os autores se basearam em Saviani (1996), que afirma que um problema não pode ser reduzido apenas a 
uma questão, mas deve, necessariamente, estar associado a uma necessidade.

Entretanto, para compreender o conceito de problema, Saviani (1996) salienta que não basta focar a palavra necessidade, uma vez que ela pode fazer com que o conceito de problema oscile em função da diversidade de cada indivíduo e da multiplicidade de situações que fazem parte do cotidiano diário de cada indivíduo. Sendo assim, destaca o problema como tendo um lado subjetivo, baseado na conscientização de uma situação de necessidade e outro objetivo, relacionado à própria situação que concretizou a necessidade. De forma mais específica, tem-se que:

A verdadeira compreensão do conceito de problema supõe [...] a necessidade. Esta só pode existir se ascender ao plano consciente, ou seja, se for sentida pelo homem como tal (aspecto subjetivo); há, porém, circunstâncias concretas que objetivizam a necessidade sentida, tornando possível, de um lado, avaliar o seu caráter real ou suposto (fictício) e, de outro, prover os meios de satisfazê-la. Diríamos, pois, que o conceito de problema implica tanto a conscientização de uma situação de necessidade (aspecto subjetivo) como uma situação conscientizadora da necessidade (aspecto objetivo) (SAVIANI, 1996, p. 14-15).

Sendo assim, esse autor se preocupa em assumir uma visão abrangente, entendendo que os aspectos subjetivos relacionados ao problema se configuram numa amplitude abrangida pela necessidade, enquanto os aspectos objetivos tratam da própria situação que gerou a necessidade. Em particular, consideramos que, embora haja uma ampliação da compreensão, estas ideias se mostram consonantes com as defendidas por Echeverría e Pozo (1998) e Onuchic e Allevato (2005), principalmente levando em consideração a seguinte afirmação de Saviani (1996, p. 14): “[...] uma questão, em si, não caracteriza o problema, nem mesmo aquela cuja resposta é desconhecida; mas uma questão cuja resposta se desconhece e se necessita conhecer; eis aí um problema”.

Apesar de concordarmos com algumas das ideias defendidas por este autor, ao nos depararmos com situações encontradas quando a MM tem como referência a realidade do mundo cibernético ${ }^{2}$, tivemos necessidade de buscar uma visão distinta e que, além de considerar os aspectos subjetivos e objetivos, acolhesse, principalmente, uma perspectiva de transformação do problema. É neste sentido que apresentamos uma visão de problema que se baseia principalmente nas ideias apresentadas por Deleuze (1988). Essa perspectiva difere da anterior por atentar para a relação entre o problema e a proposição que a ele se associa e busca, de algum modo, descrevê-lo. Nesse sentido, o autor defende que o problema não pode ser confundido com a proposição que o representa, tampouco deve ser reduzido à dúvida.

\footnotetext{
${ }^{2}$ Consideramos, embasados em autores como Bicudo e Rosa (2010) e Lévy (1996), que o universo criado pelas tecnologias digitais é uma dimensão da realidade e a adjetivamos como realidade do mundo cibernético.
} 
Em termos gerais a dúvida pode ser entendida como "[...] um estado subjetivo de incerteza, ou seja, uma crença ou opinião não suficientemente determinada, ou a hesitação em escolher entre a asserção da afirmação e a asserção da negação" (ABBAGNANO, 2007, p. 935). Tendo sua base na incerteza, a dúvida já se constitui em uma espécie de vetor que aponta na direção de possíveis respostas.

Entretanto, nem todo problema pode ser reduzido à dúvida. A natureza deles difere no sentido de que o problema não é substituído pela resposta ou deixa de ocorrer quando é resolvido. Como exemplo, Abbagnano (2007) traz que, ao encontrar a vacina de uma doença, tem-se a possibilidade de solução para o problema. Porém, essa possibilidade não elimina o problema, uma vez que não garante que a doença não ocorrerá mais. Já a dúvida, “[...] uma vez resolvida, está eliminada e é substituída pela crença” (ABBAGNANO, 2007, p. 935).

Também, seguindo nosso referencial, consideramos que o problema e a proposição que a ele se refere assumem uma distinção de natureza. Nesse sentido, Deleuze (1988) afirma que os problemas são "extra-proposicionais". A analogia que fazemos para esclarecer essa afirmação é a mesma da relação entre uma paisagem, vista pelo pintor, e o quadro desenhado por ele. Assim como a tela pintada não é a situação vista, mas sim uma representação dela, a proposição não é o problema, mas uma forma de representá-lo. Nisso devem ser levados em consideração os aspectos da linguagem usada para a representação, os aspectos que dizem respeito ao problema em si e o modo como o problema é interpretado pelos sujeitos que buscam sua determinação, isto é, a proposição que a ele se refere.

Essa proposição, ou o modo como o problema é expresso, é considerada uma forma de conduzir o problema, já indicando possíveis respostas e o caminho pelo qual o problema vai se desvelar. Nesse sentido, Deleuze (1988, p. 265) afirma:

Por si mesma, uma proposição é particular e representa uma resposta determinada.
Um conjunto de proposições pode distribuir-se de tal maneira que as respostas que
elas representem formem os casos de uma solução geral (assim, os valores de uma
equação algébrica). Mas, precisamente, gerais ou particulares, as proposições só
encontram sentido no problema subjacente que as inspira.

Com essa afirmação, o autor mostra uma visão de problema anterior à proposição que o representa. Porém, cabe salientar que, a nosso ver, a noção de "resposta" que a proposição assume, está diretamente associada à ideia que esse filósofo traz de pergunta. De modo geral, aponta que não considera existir uma biunivocidade entre problemas e questões, mas ressalva a importância da pergunta como orientadora, como uma espécie de condutor na direção da solução. Em outras palavras, a pergunta

[...] exprime, portanto, a maneira pela qual um problema é desmembrado, cunhado, traído na experiência e pela consciência, de acordo com seus casos de solução 
apreendidos como diversos. Embora nos dê uma ideia insuficiente, ela nos inspira, assim, o pressentimento do que ela desmembra (DELEUZE, 1988, p. 257).

Esse papel que a pergunta assume, conforme Deleuze (1988), está sempre atrelado ao quadro social de onde parte a inquietação, trazendo pontos de vista, considerando a experiência vivida e os possíveis interlocutores, levando em consideração as respostas passíveis de serem dadas.

Deleuze (1988), em suas argumentações, não apenas distingue o problema no modo como é representado, mas também analisa a relação existente entre este e sua solução, pois afirma que um "[...] problema se determina ao mesmo tempo em que é resolvido; mas sua determinação não se confunde com a solução: os elementos diferem por natureza, e a determinação é como a gênese da solução concomitante" (p. 267).

Para compreender essa afirmação, é importante salientar que, em suma, o problema é considerado por esse autor como uma estrutura potencial ou não atual, não se deixando apreender por nenhuma proposição que a ele se refere. À medida que há uma imersão do sujeito ou dos sujeitos no problema, há uma busca por sua determinação, que pode ser entendida, grosso modo, como uma espécie de atualização do problema, em termos de linguagem, sob a forma de proposições (interrogativas, afirmativas, descritivas, etc.).

Entretanto, o modo como é expresso já influencia e conduz a busca por soluções, isto é, a determinação do problema é o início, é a gênese que norteia a busca por uma solução. Mas essa determinação é apenas um caso particular do problema, podendo haver outras formas de interpretar e conceber a situação que está sendo investigada. Desse modo, distintas formas de conceber a situação podem levar a distintos encaminhamentos, podendo gerar distintas soluções.

Inspirado nessa perspectiva, consideramos que é possível compreender problema como um conjunto de condições não atuais e indeterminadas que dizem respeito a uma dada situação e que gera um campo de conflitos que vai assumindo um caráter mais ou menos estável, à medida que vai sendo determinado. É essa a perspectiva de problema que assumimos para o presente artigo.

\section{Metodologia e procedimentos de pesquisa}

O presente artigo visa encontrar indícios para a pergunta: como se mostra o problema no processo de Modelagem Matemática envolvido na construção de jogos eletrônicos por alunos de um curso de Licenciatura em Matemática? A metodologia utilizada para realizar 
essa investigação foi a qualitativa, cujo propósito fundamental, conforme Santos Filho e Gamboa (2000) e Bogdan e Biklen (1994), é a compreensão, a explanação e a interpretação do fenômeno estudado, o que entendemos estar em consonância com a pergunta que propusemos.

Para buscar respostas ao questionamento norteador, ministramos um curso intitulado "Construção de Jogos Eletrônicos". Participaram do curso oito alunos de graduação de um curso de Licenciatura em Matemática. As atividades ocorreram ao longo de oito sábados, de maio a julho de 2009, no Laboratório de Ensino e Aprendizagem com Tecnologias, das 8h às $12 \mathrm{~h}$, somando um total de 4 encontros.

O principal programa usado na construção dos jogos foi o Scratch, que é um software livre desenvolvido no MIT (Massachusetts Institute of Technology). Constitui-se como uma linguagem de programação visual e permite ao usuário construir interativamente suas próprias histórias, animações, jogos, simuladores, ambientes visuais de aprendizagem, músicas e arte. Os comandos são visualizados por meio de blocos que são arrastados para uma área específica e conectados, formando a programação do ambiente (Figura 2).

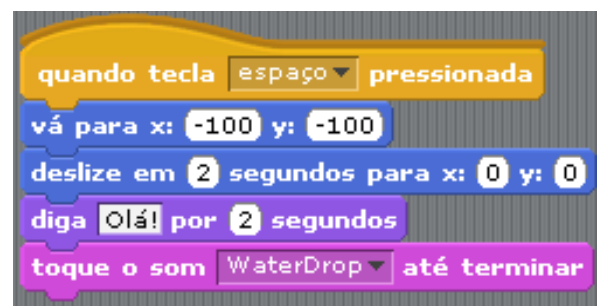

Figura 2 - Programação no Scratch.

Fonte: Dados da pesquisa (2012).

O conjunto de informações provenientes das falas, interações entre os participantes, interações com os software e outras mídias e gestos, constituíram parte fundamental do acervo de dados que foram utilizados na busca por respostas à questão norteadora. Tais dados foram capturados por filmagens em câmeras e, principalmente, por meio do software Camtasia. Este último permitiu que, em um mesmo vídeo, fossem capturados a imagem da tela do computador e imagem e som das discussões envolvendo os participantes. Durante a segunda etapa do curso foram realizadas 16 gravações de 3,5 horas cada, em média, totalizando 56 horas de gravação.

Em termos metodológicos, a utilização de vídeos é defendida por Powell, Francisco e Maher (2004) que afirmam existir pelo menos dois ganhos potenciais de registros ao utilizar essa forma de armazenamento de dados como uma fonte de pesquisa: a densidade e a permanência. Segundo eles, a densidade tem como vantagem sobre um observador a capacidade de monitorar eventos simultâneos de forma detalhada, revelando diferentes 
comportamentos desenvolvidos bem como a vantagem de possibilitar áudio e vídeo simultaneamente. Quanto à permanência, refere-se à possibilidade de rever várias vezes os acontecimentos vivenciados, auxiliando na eficácia da análise:

Análises detalhadas de vídeos e de dados longitudinais, assim como os de curto prazo, tornam-se mais eficazes a partir de múltiplas sessões de visualização. $\mathrm{O}$ vídeo não apenas nos permite múltiplas visões, mas também possibilita visões sobre múltiplos pontos de vista (POWELL, FRANCISCO, MAHER, 2004, p. 91).

A análise dos dados consistiu-se em um olhar atento e reflexivo frente aos acontecimentos do processo de construção dos modelos que compõem os jogos eletrônicos elaborados pelos alunos. Norteados pela pergunta diretriz, os dados gravados no Camtasia foram transcritos. Essa transcrição envolveu todas as falas dos participantes ao longo do processo de construção dos jogos. Posteriormente esses dados foram organizados, buscando uma nova leitura, levando em consideração as anotações feitas durante o processo de produção, a troca de ideias com os pares e as inquietações levantadas ao longo, tanto da transcrição, quanto da revisão de literatura.

As reflexões frente às primeiras impressões fizeram com que parte da sustentação teórica fosse repensada. Dentre os elementos revistos, a ideia de problema foi um dos que se mostrou relevante a nós, apresentando características que mostravam processos distintos do que a literatura tratava. Desse modo, embora neste artigo tenhamos apresentado o referencial de problema anterior aos dados, na sequencialidade temporal da investigação ele foi feito a posteriori, consequência da imersão nos dados.

Assumida uma visão de problema, foram criados episódios, entendidos como "histórias" que dizem respeito aos fatos ocorridos ao longo da produção de dados, que mesclam transcrições literais e análises frente às ações e posicionamentos tomados pelos envolvidos nas construções dos jogos eletrônicos, trazendo luz à questão orientadora. Devido à linguagem específica dada pela própria natureza do Scratch, optamos por associar aos episódios, sempre que necessário, imagens que se referem tanto aos modelos criados pelos alunos, quanto à atualização deles no jogo.

Buscando atender aos critérios éticos, foi solicitado aos estudantes autorização para utilização dos dados. Os nomes usados nas transcrições feitas foram fíctícios, pretendendo com isso preservar a identidade de cada participante. Com vistas a um melhor entendimento do processo de análise e para uma melhor contextualização, apresentaremos na próxima seção recortes do episódio que gerou as discussões apresentadas nesse artigo.

\section{O problema e a Modelagem Matemática: o que mostram os dados?}


Apresentaremos o episódio que nomeamos por "Movimento do Carro", que trata do processo de construção de um modelo, escrito na linguagem Scratch, que condiciona o movimento de um objeto representado graficamente pela imagem de um automóvel. Destacamos que, para o escopo abrangido por este artigo, compreenderemos as construções feitas por meio do Scratch, como modelos matemático-tecnológicos. Esses modelos, por terem sua base dada pela tecnologia, podem incorporar em sua estrutura aspectos sonoros e estético-visuais, abrangendo também elementos da língua falada, configurando assim um tipo de modelo que se diferencia daqueles que comumente são utilizados em uma linguagem matemática formal.

Buscando ainda reforçar as associações com a Modelagem Matemática, salientamos que entendemos a construção de um jogo eletrônico como a reunião de pequenos modelos específicos, que tratam das particularidades e problemáticas encontradas em cada aspecto que constitui o próprio jogo. Assim, aspectos como movimentação de objetos, entrelaçamentos entre diferentes objetos e fluxos condicionais são analisados como problemas específicos e possuem construções (modelos) específicas que os determinam e conduzem.

$\mathrm{Na}$ especificidade deste artigo apresentamos o problema que envolve a movimentação de um objeto buscando fazer com que sua atualização na tela do computador permaneça em uma região visual específica. Esse problema envolve as discussões e construções feitas pela dupla de estudantes Ana e Laura (nomes fictícios), no dia 17 de julho de 2009. Também participaram dos diálogos o professor/pesquisador (P) e o monitor (V) que estavam presentes nesse dia. Nesse encontro, a participante Ana não compareceu, portanto os diálogos são compostos, em sua maioria, pelas falas da estudante Laura e do professor/pesquisador.

O objetivo da dupla era criar um objeto carro que desviaria de outros objetos que seriam tomados como obstáculos colocados em uma pista. Com esse intuito, partiram para a construção do cenário e dos elementos que constituiriam o jogo. Após encontrarem uma figura para o cenário do jogo, dedicaram seu tempo a modelar a interação dos obstáculos, observando posição, velocidade, deslocamento e aspecto visual. Iniciaram, ainda, a construção do modelo que estava associado ao movimento do carro. Criaram uma estrutura que envolvia o objeto carro e um conjunto de comandos relativos a esse que pode ser visualizado ${ }^{3}$ na Figura 3.

\footnotetext{
${ }^{3}$ Ao longo da apresentação dos dados a qualidade das figuras poderá variar. Tal fato ocorre, pois parte das imagens foram coletadas diretamente do vídeo, enquanto outras puderam ser acessadas diretamente do arquivo do jogo feito nessa data, o que, nesse último caso, garante uma qualidade melhor.
} 


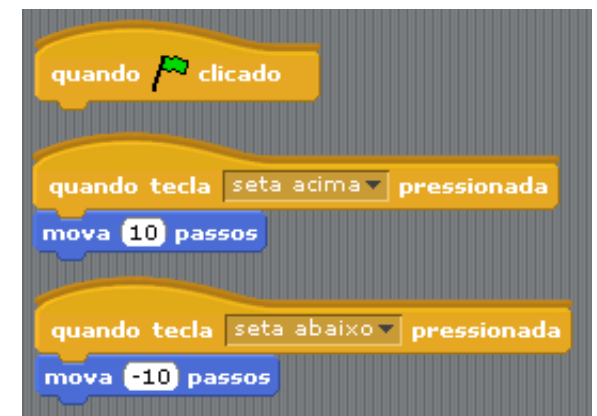

Figura 3 - Comandos que se referem ao movimento do carro Fonte: Dados da pesquisa (2012).

Como em alguns jogos eletrônicos, as participantes optaram por manter o objeto carro em um posicionamento horizontal constante no lado esquerdo da tela, limitando seus movimentos no sentido vertical apenas. É justamente esse movimento que a Figura 5 apresenta, na qual podem ser observadas três linhas de comando. A primeira (de cima para baixo) refere-se ao início do jogo. Quando a bandeira verde ${ }^{4}$ é clicada, inicia-se determinada sequência de comandos (no caso, não há comando associado a esse controle). O segundo e o terceiro blocos de comando referem-se aos movimentos programados para as setas do teclado. Quando a tecla "seta acima" é clicada, o objeto que se refere a esse comando (no caso, o carro) se movimentará 10 passos na direção vertical (eixo cartesiano y), no sentido para cima. De forma similar, quando a tecla (seta abaixo) for clicada, o objeto se movimentará -10 passos na direção vertical, isto é, se movimentará 10 passos para baixo.

Como não há limitações para a altura atingida, o objeto se movimentará por todo espaço destinado ao jogo (que possui uma amplitude eixos cartesianos que varia de -230 a 230 espaços). Para dar a sensação de movimento (uma vez que o objeto carro fica imóvel horizontalmente), as alunas optaram por movimentar o obstáculo na direção do carro. $\mathrm{O}$ aspecto visual do jogo (aquilo que aparece na área denotada por estágio) pode ser visto na Figura 4.

\footnotetext{
${ }^{4}$ Para iniciar qualquer jogo no Scratch é necessário dar um comando inicial. Esse comando inicial consiste na bandeira verde.
} 


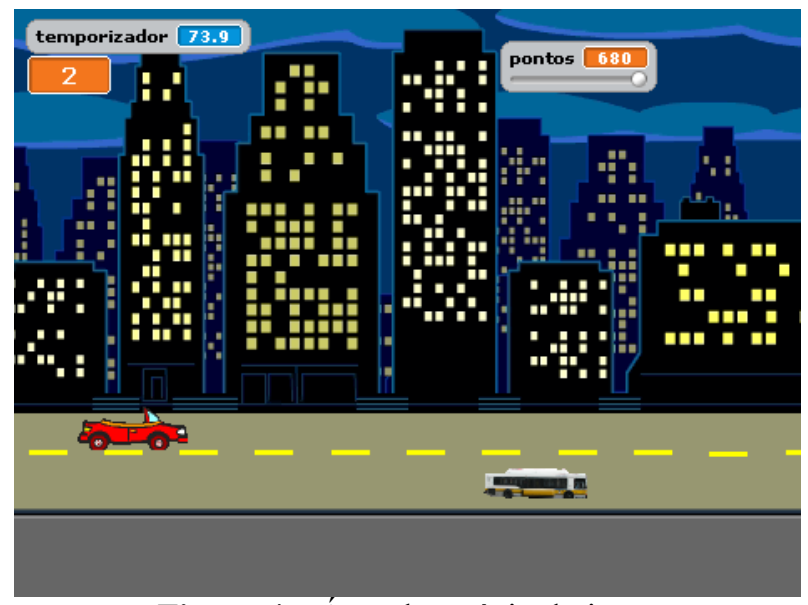

Figura 4 - Área de estágio do jogo.

Fonte: Dados da pesquisa (2012).

A seguir fazemos uma explanação que envolve as modificações ocorridas no modelo apresentado na Figura 3, que possibilita o movimento do objeto carro, iniciando com a apresentação do Excerto 1, no qual a estudante Laura chama P no início do encontro.

\section{Excerto 1: O carro voador}

Laura: Uma coisa que ficou da última aula. Vai começar o jogo, mas então vai lá em cima. [mostra, mexendo a posição do carro com as setas do teclado, que ele vai até o topo da tela, extrapolando o espaço delimitado para a estrada (Figura 6)]

P: Aham! É um carro voador, não é? [risos]

Laura: Isso! [risos]

Fonte: Gravação de vídeo, 17/07/2009

Laura encaminhou outros questionamentos que são discutidos com o professor e depois de alguns minutos retoma a situação do movimento do carro.

Excerto 2: E para ele não flutuar?

Laura: E para ele não flutuar?

P: Para o quê?

Laura: Para ele não flutuar!

P: Ah, tá! Vamos ver.

P: Tem que colocar alguns condicionadores também. Ele vai ficar parado aí, não é? [Referindo-se à movimentação no sentido horizontal].

Laura: Ele para.

P: Ele para ou ... "mova” zero passos.

P: Ou... não mova mais. Então pode colocar, mude X por Y, tu pode colocar um "se". Um "se senão"...

Laura: No meio disso aqui [dos comandos] bota um "se senão", então?

P: É. Não sei se "se senão" ou "se". Teria que testar para ver o que vai funcionar. Mas acho que é isso.

Fonte: Gravação de vídeo, 17/07/2009

Por meio desse excerto é possível observar que o modelo construído (Figura 3) permite que o carro se movimente em um padrão que extrapola as limitações dadas pela 
estrada. Influenciada pelas sugestões do professor, Laura inicialmente tentou usar o comando "se senão". Sua dificuldade inicial consistiu em considerar situações distintas em um mesmo modelo, isto é, além do carro não se mover dentro do espaço vertical desejado (na "estrada"), havia a necessidade de desviar de obstáculos que surgiam na pista (Figura 5).

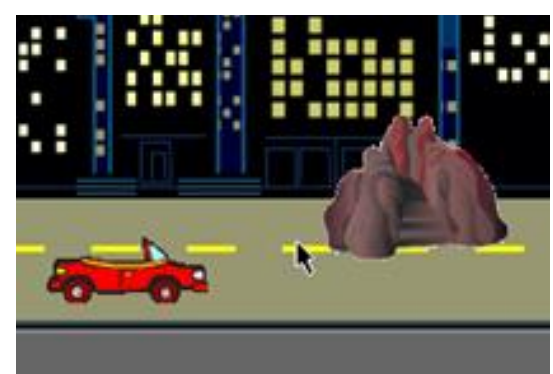

Figura 5 - Objetos carro e obstáculo

Fonte: Dados da pesquisa (2012).

O objeto carro, ao sobrepor ("encostar") o (no) objeto obstáculo, não sofria nenhuma alteração em seu movimento, mantendo posição e "velocidade", sem qualquer interferência. O desejo de mudar esse aspecto, isto é, de fazer com que algo acontecesse quando houvesse sobreposição dos objetos fez com que Laura modificasse os comandos até então construídos. Nosso olhar atento ao problema "bater/encostar" revelou um entrelaçamento de múltiplos acontecimentos envolvendo outros problemas, argumentações e inquietações que, por sua vez, orientaram ações que implicaram em soluções ou novos problemas ou discussões, criando assim uma trama cuja complexidade não se mostrou de modo linear, no sentido temporal. $\mathrm{Na}$ Figura 6 é possível acompanhar o fluxo de desdobramentos que envolveu esse problema, desde sua determinação inicial até encontrar uma solução específica.

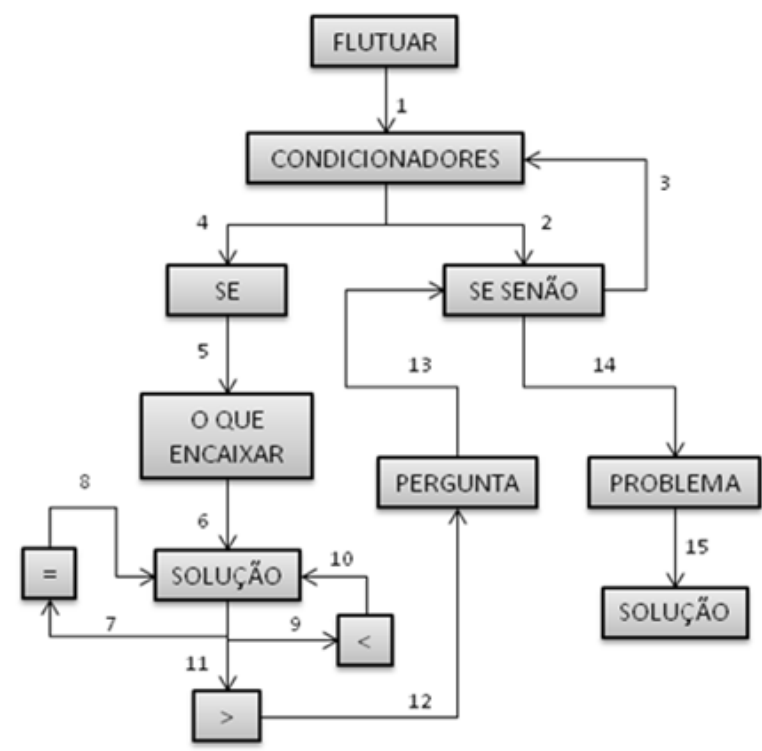

Figura 6 - Fluxograma relacionado ao problema Fonte: Dados da pesquisa (2012). 
Avaliamos esse problema a partir da pergunta apresentada pela estudante Laura, quando diz: E para ele não flutuar? (Excerto 2) mostrando com isso sua preocupação com o movimento do objeto carro, que extrapola a região de movimentação (estrada) estipulada pela estudante.

Embora na visão de Deleuze (1988) o problema não possa ser confundido com pergunta, esse autor revela que um dos modos de o problema se determinar é pelo modo interrogativo. Essa enunciação, segundo Deleuze (2011), leva em consideração tanto as experiências daquele que enuncia quanto dos envolvidos na conversa. No caso específico da pergunta enunciada por Laura, esta é dirigida ao professor pesquisador, que supostamente poderia auxiliar na busca por respostas. É justamente essa busca por possibilidades de respostas que a estudante encontra na continuação da conversa no Excerto 2, quando $\mathrm{P}$ apresenta, como um possível encaminhamento, o uso de condicionadores: "Tem que colocar alguns condicionadores também. Ele vai ficar parado aí, não é?".

Assim, a pergunta apresentada pela estudante se desmembra, por meio da interlocução com o professor, em possibilidades de soluções, o que está em consonância com as ideias de Deleuze (1988, p. 267), quando diz que a pergunta “[ [... exprime [...] a maneira como o problema é desmembrado", podendo influenciar de modo direto na busca por uma solução.

Apesar de influenciar de modo decisivo a busca por uma solução, a fala de $\mathrm{P}$ não se mostra somente neste aspecto, uma vez que pode ser considerada também como uma forma distinta de apresentar o problema. O que observamos com isso é que há nela um aspecto dual que, de um lado responde à determinação inicial do problema (no sentido de ser conduzido por ela) e, de outro, a altera apresentando outro enfoque (uma nova atualização do problema), relacionado ao uso de condicionadores.

Assim, o modo como o problema é compreendido passa de "flutuar" para "condicionadores" havendo uma determinação que busca uma adaptação à linguagem usada na construção do jogo eletrônico. Nesse sentido, o que observamos é que o processo de solução do problema também está associado à própria determinação do problema, ou, nas palavras de Deleuze $(1988$, p. 267), o “[...] problema se determina ao mesmo tempo em que é resolvido".

Outro aspecto que consideramos importante é o significado da dúvida, entendida como sendo “[...] um estado subjetivo de incerteza, ou seja, uma crença ou opinião não suficientemente determinada, ou a hesitação em escolher entre a asserção da afirmação e a asserção da negação" (ABBAGNANO, 2007, p. 348). Deleuze (1988) afirma que, assim como a pergunta, a dúvida não pode ser colocada em biunivocidade com problema. 
Porém, essa pode assumir um papel, tanto do processo de delimitação das soluções, quanto na determinação do problema. Um exemplo disso pode ser observado na continuação da fala de P quando sugere o uso de condicionadores. Apesar de encaminhar uma solução, o pesquisador se mostra em dúvida quanto ao que fazer, expressando isso nas seguintes falas: “É, não sei se um 'se senão' ou um 'se”, (Excerto 2). Nesse momento, P indica dois encaminhamentos possíveis, por meio do uso do comando condicional "se" e por meio do uso do comando condicional "se senão".

Ao observar novamente o Fluxograma apresentado na Figura 6, é possível ver que a determinação do problema, quando associada ao uso de condicionadores, se bifurca em dois grandes eixos (que se entrelaçam), um conduzido pelo uso do comando "se" e outro pelo uso do "se senão". Assim, há na dúvida apresentada, não somente um avanço na determinação do problema, conforme defende Deleuze (1988), mas também há uma delimitação no conjunto de condicionadores que abrange somente dois casos, implicando de modo direto nas construções feitas pela estudante.

\section{Reflexões sobre os dados e considerações finais}

Para o escopo do presente artigo, nos propusemos a nos orientar pela pergunta: como se mostra o problema no processo de Modelagem Matemática envolvido na construção de jogos eletrônicos por alunos de um curso de Licenciatura em Matemática? Ao analisarmos os dados e argumentações expostas, é possível observar que, ao longo do processo de MM, a imersão no problema vai desmembrando-o em determinações mais específicas, as quais são inspiradas por dúvidas, perguntas, afirmações que, por sua vez, conduzem a soluções para o problema.

Isso apresenta o problema como um fluxo que se desenvolve e se mostra somente no próprio caminho percorrido, ou, conforme Deleuze (1988) defende, determina-se ao longo do próprio processo que envolve a busca por uma solução. A cada nova determinação, novas possibilidades são consideradas, direcionando o campo problemático que tem como consequência final ações transformadoras da organização do jogo eletrônico (no caso). Este aspecto pode ser observado no fluxograma apresentado pela Figura 6, no qual o "flutuar" se desdobra no uso de "condicionadores" que, por sua vez se bifurcam, formando dois fluxos a entrelaçar-se de modo não necessariamente linear e conduzem a constantes transformações nos modelos construídos.

Destacamos que essa não linearidade não está relacionada especificamente à 
sequencialidade temporal que é enumerada na Figura 6, mas sim em comparação a aspectos trazidos pela literatura da MM, que, algumas vezes, tratam o problema como algo estático e que, uma vez determinado, impulsiona o processo de modo cíclico e sequencial. Assim, consideramos que o problema analisado não pode ser visto como algo estático, pré-definido, mas sim de modo fluido.

Consideramos que essa mudança, que ocorre ao longo dos fluxos apresentados, mostra que o problema vai se (trans)formando com a imersão dos envolvidos nele e, a cada nova proposição que, de alguma forma, determina o problema, o fluxo se renova, como, por exemplo, o uso da expressão "É, não sei se um se senão ou um se", por $\mathrm{P}$, que influenciou o aparecimento de dois fluxos dados pelo "se" e pelo "se senão" na Figura 6.

Dessa forma, a proposição que se refere ao problema não deve ser confundida com o próprio problema, mas como uma determinação que conduz a ações que buscam resolver o problema e, portanto, estão relacionadas à solução. Por outro lado, é importante salientar que essas variações que o fluxo sofre, apresentadas em termos proposicionais, não assumem um caminho que é independente do problema da qual derivam (DALLA VECCHIA; MALTEMPI, 2012). Assim é o caso apresentado no episódio analisado nesse artigo, que, apesar de assumir particularidades em cada ramo do fluxo, não está dissociado do problema inicial, que diz respeito ao posicionamento do objeto carro. Esse aspecto é apresentado por Deleuze (1988, p. 265), quando diz que, “[...] gerais ou particulares, as proposições só encontram sentido no problema subjacente que as inspira".

Ainda, consideramos que podemos inferir que não somente o modo como o problema é compreendido pelos participantes condiciona a busca por uma solução, mas há também outros aspectos que devem ser considerados como a produção do jogo em si, a perspectiva de que os modelos construídos foram feitos para serem atualizados na realidade do mundo cibernético, os objetivos dos participantes e do pesquisador e, principalmente, o referencial usado (linguagem de programação Scratch). Assim, há condições inicias que também conduzem o processo de resolução da situação envolvida.

Destacamos que, apesar dos aspectos apresentados neste artigo partirem de situações particulares, tratadas na construção de jogos eletrônicos que encontram na realidade do mundo cibernético um espaço para atualização, entendemos que a associação ao referencial teórico não se restrinja somente a esse contexto.

De fato, em nossas investigações temos nos inspirado nas discussões acerca de problema para abranger contextos clássicos da Modelagem Matemática, como é o caso de aplicações de otimização linear com restrições. Esse aspecto pode ser observado em 
Weingarten e Dalla Vecchia (2017), que tratam também do processo de determinação do problema, porém focando trabalhos aplicados e desenvolvidos por estudantes do curso de Engenharia de Produção de uma universidade do sul do Brasil. Desse modo, entendemos que a abrangência das associações teóricas apresentadas não se limitam somente ao trabalho com o Scratch e com o uso de tecnologias digitais.

Para finalizar, consideramos que as ideias discutidas neste artigo estão ajudando a ampliar discussões acerca da MM, principalmente quando associada às tecnologias digitais. Em particular, colocar aspectos em suspensão, como a sequencialidade do processo de MM apresentada na literatura, contribui para a compreensão da condução e do entendimento do próprio processo de MM. O que se evidencia na investigação feita é um processo de contínua transformação, mostrando que a determinação do problema não é algo que se apresenta $a$ priori, mas que faz parte de um entrelaçamento que se confunde com o próprio fazer. Além desse aspecto, há outros que tangenciam a proposta investigativa apresentada e que estão relacionados à MM, como a discussão de modelo, realidade e objetivos pedagógicos. Entrelaçar esses aspectos de modo consistente e não superficial faz parte de nossas investigações atuais e futuras.

\section{Referências}

ABBAGNANO, N. Dicionário de filosofia. São Paulo: Martins Fontes, 2007.

ARAÚJO, J. L. Cálculo, tecnologias e modelagem matemática: as discussões dos alunos. 2002. $173 \mathrm{f}$ f. Tese (Doutorado em Educação Matemática) - Instituto de Geociências e Ciências Exatas, Universidade Estadual Paulista, Rio Claro, 2002.

BARBOSA, J. C. Modelagem Matemática: Concepções e Experiências de Futuros Professores. 2001. 253f. Tese (Doutorado em Educação Matemática) - Instituto de Geociências e Ciências Exatas, Universidade Estadual Paulista, Rio Claro, 2001.

BASSANEZI, R. C. Ensino-aprendizagem com Modelagem Matemática. 2.ed. São Paulo: Contexto, 2004.

BICUDO, M. A. V.; ROSA, M. Realidade e Cibermundo: horizontes filosóficos e educacionais antevistos. Canoas: Editora da ULBRA, 2010.

BIEMBEnGUT, M. S.; HEIN, N. Modelagem Matemática no Ensino. São Paulo: Contexto, 2007.

BOGDAN, R; BIKLEN, S. Investigação Qualitativa em Educação: uma introdução à teoria e aos métodos. Lisboa: Porto Editora, 1994.

BORBA, M. C.; MALHEIROS, A. P. S.; ZULATTO, R. B. A. Educação a Distância online. Belo Horizonte: Autêntica, 2007.

BORROMEO FERRI, R.; BLUM; W. Insights into Teachers' Unconscious Behaviour in Modeling 
Contexts. In: LESH, R. et al. (Org.). Modeling Students' Mathematical Modeling Competences. New York: U.S.A., Springer, 2010. p. 423-432.

DALLA VECCHIA, R.; MALTEMPI, M. V. Ensaio Sobre a Modelagem Matemática e o Virtual. In: XIII Encontro Brasileiro de Estudantes de Pós-Graduação em Educação Matemática, Anais... Goiânia, 2009. p. $1-15$

DALLA VECCHIA, R. A Modelagem Matemática e a Realidade do Mundo Cibernético. 2012. 275f. Tese (Doutorado em Educação Matemática) - Instituto de Geociências e Ciências Exatas, Universidade Estadual Paulista, Rio Claro, 2012.

DALLA VECCHIA,R.; MALTEMP M. V. Modelagem Matemática e Tecnologias de Informação e Comunicação: a realidade do mundo cibernético como um vetor de virtualização . Bolema, v.26, n. 43, 2012. p. $963-990$

DELEUZE, G. Diferença e Repetição. Traduzido por: Orlandini, L.; Machado, R. Tradução de: Différence et Répétition. Rio de janeiro: Graal, 1988.

DELEUZE, G. Lógica do sentido. 4. ed. São Paulo: Perspectiva, 2011.

DELEUZE, G.; GUATTARI, F. O que é a Filosofia? 2. ed. São Paulo: Editora 34, 1993.

ECHEVERRÍA, M. P. P.; POZO, J. I. Aprender a resolver problemas e resolver problemas para aprender. In: POZO, J. I. (Org.). A solução de problemas. Porto Alegre: Artes Médicas, 1998. p. 13 42.

GRANGER, G., G. A Ciência e as Ciências. São Paulo: Editora da Universidade Estadual Paulista, 1994.

JAVARONI, S. L. Abordagem geométrica: possibilidades para o ensino e aprendizagem de Introdução às Equações Diferenciais Ordinárias. 2007. 231 f. Tese (Doutorado em Educação Matemática) - Instituto de Geociências e Ciências Exatas, Universidade Estadual Paulista, Rio Claro, 2007.

KAISER, G.; SCHWARZ, B., TIEDEMANN, S. Future Teachers' Professional Knowledge on Modeling. In: LESH, R. et al. (Org.). Modeling Students' Mathematical Modeling Competences. New York: U.S.A., Springer, 2010. p. 433 - 444.

KLÜBER, T. E. Uma Metacompreensão da Modelagem Matemática na Educação Matemática. 2012. 396f. Tese (Doutorado em Educação Científica e Tecnológica) - Programa de Pós Graduação em Educação Científica e Tecnológica, Universidade Federal de Santa Catarina, Florianópolis, 2012.

LÉVY, P. O que é o virtual. São Paulo: Editora 34, 1996.

MALHEIROS, A. P. S. Educação Matemática Online: a elaboração de projetos de Modelagem. 2008. 187f. Tese (Doutorado em Educação Matemática) - Instituto de Geociências e Ciências Exatas, Universidade Estadual Paulista, Rio Claro, 2008.

ONUCHIC, L. R.; ALLEVATO, N. S. G. Novas reflexões sobre o ensino-aprendizagem de matemática através da resolução de problemas. In: BICUDO, M. A. V.; BORBA, M. C. (Org.). Educação Matemática: pesquisa em movimento. São Paulo: Cortez editora, 2005. p. 169-187.

POLLAK, H. Mathematical modelling: a conversation with Henry Pollak. In: BLUM, W. et al. (Ed.). Modelling and applications in mathematics education. New York: Springer, 2007. p. 109-120. 
POWELL, A. B.; FRANCISCO, J. M.; MAHER, C. A. Uma Abordagem à Análise de Dados de Vídeo para Investigar o Desenvolvimento de Idéias e Raciocínios Matemáticos de Estudantes. Bolema, v. 17, n. 21, p. 81-140, Unesp: Rio Claro, 2004.

SANTOS FILHO, J. C. O.; GAMBOA, S. Pesquisa Educacional: quantidade-qualidade. São Paulo: Cortez, 2000.

SAVIANI, D. Educação: do senso comum à consciência filosófica. 11. ed. São Paulo: Editores associados, 1996.

WEINGARTEN, T. Modelagem Matemática: um enfoque na transformação da determinação do problema. 2015. 124 f. Dissertação (Dissertação em Ensino de Ciências e Matemática) - Programa de Pós Graduação em Ensino de Ciências e Matemática, Universidade Luterana do Brasil, Canoas, 2015.

WEINGARTEN, T.; DALlA VECCHIA, R. Problema, Sentido e Significado: a multiplicidade em Modelagem Matemática. Ciência e Educação, v. 23, n. 1, p. 219-235, 2017, Unesp: Bauru, 2017.

Submetido em 07 de Março de 2018. Aprovado em 27 de Novembro de 2018. 